FERREIRA, M.A.J.F.; QUEIROZ, M.A.; BRAZ, L.T.; VENCOVSKY, R. Correlações genotípicas, fenotípicas e de ambiente entre dez caracteres de melancia e suas implicações para o melhoramento genético. Horticultura Brasileira, v. 21, n. 3, p. 438-442, julho-setembro 2003.

\title{
Correlações genotípicas, fenotípicas e de ambiente entre dez caracteres de melancia e suas implicações para o melhoramento genético
}

\author{
Maria Aldete J.F. Ferreira ${ }^{1}$; Manoel Abílio de Queiróz ${ }^{2}$; Leila T. Braz ${ }^{3}$; Roland Vencovsky ${ }^{4}$ \\ ${ }^{1}$ Embrapa Roraima, C. Postal 133, 69301-970 Boa Vista-RR; E-mail: aldete@cpafrr.embrapa.br; ${ }^{2}$ Embrapa Semi-Árido, C. Postal 23, \\ 56300-970 Petrolina-PE; E-mail: mabilio@cpatsa.embrapa.br; ${ }^{3}$ UNESP, Rod. Paulo Donato Castellane km 5, 14870-000 Jaboticabal-SP; \\ E-mail: 1tbraz@fcav.unesp.br; ㅌESALQ-USP, C. Postal 83, 13400-970 Piracicaba-SP; E-mail: vencovsk@terra.com.br
}

\section{RESUMO}

Foram estimadas as correlações genotípicas, fenotípicas e de ambiente entre os caracteres número de dias para o aparecimento da primeira flor feminina $(\mathrm{FF})$; número de frutos por planta $(\mathrm{NF})$; peso de frutos por planta (PF); cor (CP) e espessura (EP) da polpa; diâmetro longitudinal (DL) e transversal (DT) de frutos; teor de sólidos solúveis (TS); número de sementes (NS) e peso de 100 sementes (PS) por fruto. As populações de melancia B9, 'Charleston Gray', 'Crimson Sweet', 'New H. Midget', M7, P14 e B13, os 21 híbridos $\mathrm{F}_{1}$, em dialelo, e seus recíprocos foram avaliados em campo, de acordo com o delineamento em blocos ao acaso completos, com quatro repetições. Houve grande similaridade entre as estimativas das correlações genotípicas e fenotípicas investigadas. Foram verificadas correlações genotípicas importantes entre os caracteres NF e PF, DL e DT; entre PF e DL, DT, EP e TS e entre CP e FF, EP e TS. Tais correlações indicam que o aumento no número de frutos por planta está correlacionado com a redução do peso de frutos e do tamanho dos frutos (função de DL e DT) e que o aumento no peso dos frutos está associado ao aumento no tamanho dos frutos, da espessura e teor de sólidos solúveis da polpa, assim como a polpa vermelha está relacionada à precocidade e ao aumento na espessura e no teor de sólidos solúveis da polpa. As associações indesejáveis entre os caracteres, como entre número de frutos por planta e cor da polpa e número de frutos por planta e teor de sólidos solúveis, não foram completas, indicando, portanto, a possibilidade de se obter indivíduos recombinantes a partir de populações segregantes sintetizadas através de intercruzamentos de populações contrastantes.

Palavras-chave: Citrullus lanatus, correlações, caracteres, pré-melhoramento, dialelo.

\section{ABSTRACT}

Genotypic, phenotypic and environmental correlations among agronomic traits and the consequences for watermelon breeding

Genotypic, phenotypic and environmental correlations were estimated among the following traits of watermelon: number of days to the appearance of the first female flower ( $\mathrm{FF})$; number of fruits per plant (NF); weight of fruit (PF); flesh color (CP) and thickness (EP); longitudinal (DL) and transversal (DT) fruit diameter; sugar content (TS); number of seeds (NS) and weight of 100 seeds (PS) per fruit. The watermelon populations B9, Charleston Gray, Crimson Sweet, New H. Midget, M7, P14 and B13, their $21 \mathrm{~F}_{1}$ hybrids in diallel crosses and corresponding reciprocals were evaluated in the field, through a randomized complete block design with four replications. A great similarity among the estimates of genotypic and phenotypic correlation was found. Interesting genotypic correlations were observed between NF and PF, DL and DT; between PF and DL, DT, EP and TS and between CP and FF, EP and TS. Such correlations indicated that an increase in the number of fruits per plant is correlated with a reduction in the fruit weight and fruit size (function of DL and DT) and that an increase of fruit weight is associated with an increase in fruit size, thickness and sugar content. In addition, red flesh color was related with earliness and with increments of traits thickness and sugar content. The undesirable associations detected between number of fruits per plant and flesh color and number of fruits per plant and sugar content, however, was not sufficiently strong, indicating that it is possible to obtain recombinant individuals in segregating populations synthesized through crosses among contrasting populations.

Keywords: Citrullus lanatus, correlation, characters, prebreeding, diallel.

(Recebido para publicação em 08 de março de 2002 e aceito em 22 de abril de 2003)

A melancia (Citrullus lanatus) des aca-se entre as principais cucurbitáceas cultivadas no Brasil, sendo que a produtividade média é de $30 \mathrm{t} /$ ha (IBGE, 1998). Os principais estados produtores são Maranhão, Bahia, Piauí, São Paulo, Goiás, Santa Catarina e Pernambuco, sendo a região Nordeste responsável por $55,6 \%$ da produção nacional (IBGE, 1991).

No Nordeste, centro de diversidade da melancia, esta cucurbitácea é de grande importância econômica e cultural desde a época do Brasil Colônia, quan- do foi introduzida pelos escravos africanos (Romão, 1995). Nessa região, evidentemente, encontra-se ampla variabilidade genética, como já foi constatado em relação às principais características da planta e de frutos (Assis, 1994, 1999; Dias et al., 1996; Ferreira, 1996, 2000; Ferreira et al., 2000; Queiróz, 1993, 1998; Queiróz et al., 1996, 1999, 2000). Contudo, as cultivares de melancia disponíveis no mercado brasileiro são, na sua grande maioria, de origem americana e suscetíveis a muitas doenças e pragas. Entre as culti- vares, a 'Crimson Sweet' é a que apresenta maior área cultivada, acarretando no fornecimento de, praticamente, apenas uma cultivar para o mercado consumidor. Além desses fatos, essa cultivar caracteriza-se por apresentar frutos grandes, o que implica em falta de opções para os consumidores que preferem frutos menores. A preferência, tanto no Brasil quanto em outros países, tem sido por frutos pequenos. Esta tendência pode promover oportunidades para o mercado externo, uma vez que os consumidores têm buscado frutos 
pesando entre quatro a seis quilos, e em casos mais extremos, como o mercado japonês, frutos com aproximadamente dois quilos. Além desse caráter, outros são igualmente importantes, como a prolificidade, a cor da polpa, o teor de sólidos solúveis, o formato do fruto, o número de sementes por fruto e a resistência a doenças. O consumo de frutos de melancia sem sementes também deverá aumentar no Brasil, acompanhando a tendência do mercado externo. Nos Estados Unidos cerca de $35 \%$ do mercado consumidor prefere melancias sem sementes.

Diante destes fatos, fica evidente a importância do desenvolvimento de programas de melhoramento genético nacional, que tenham como objetivo a obtenção de cultivares resistentes às principais doenças e pragas, bem como a melhoria na qualidade dos frutos, visando suprir o mercado produtor e consumidor, os quais estão cada vez mais exigentes. A Embrapa Semi-Árido apresenta um programa amplo, cujos objetivos abrangem desde a área de recursos genéticos até a obtenção de variedades e híbridos com boas características de plantas e de frutos, incluindo frutos sem sementes.

Geralmente, os programas de melhoramento têm por finalidade obter cultivares aprimoradas para um conjunto de caracteres. Por isso, o conhecimento da natureza e magnitude das correlações entre os caracteres de interesse é de fundamental importância. As relações existentes entre os caracteres são, em geral, avaliadas por meio das correlações genotípicas, fenotípicas e de ambiente. A correlação fenotípica é estimada diretamente de medidas fenotípicas, sendo resultante, portanto, de causas genéticas e ambientais. Apenas a correlação genotípica, que corresponde à porção genética da correlação fenotípica, é empregada para orientar programas de melhoramento, por ser a única de natureza herdável. De acordo com Cruz et al. (1988) e Vencovsky \& Barriga (1992), estudos dessa natureza fornecem informações importantes para o melhoramento genético, como a possibilidade de: a) identificar a proporção da correlação fenotípica que é devida a causas genéticas; b) verificar se a seleção em um caráter afeta outro; c) quantificar ganhos indiretos devido à seleção efetuada em caracteres correlacionados e; d) avaliar a complexidade dos caracteres.
Para exemplificar, caso dois caracteres estejam correlacionados, é possível obter ganho em um deles por meio da seleção indireta do outro. Isto é vantajoso, principalmente, quando um caráter, de alto valor econômico, possui baixa herdabilidade ou é de difícil avaliação, quando comparado a outro caráter que está associado a ele. Desta forma, podese selecionar com base naquele que apresenta alta herdabilidade ou é de fácil avaliação visando melhorar o outro.

No caso da melancia, a produção e o número de frutos por planta, segundo Ferreira (2000), apresentam, respectivamente, 20 e $53 \%$ de herdabilidade, ou seja, são consideravelmente influenciados pelo ambiente. Contudo, estes caracteres poderão estar correlacionados com outros que sejam menos influenciados pelo ambiente ou de fácil avaliação, como por exemplo com o peso ou o tamanho dos frutos ou a cor, a espessura ou o teor de sólidos solúveis da polpa que, de acordo com Ferreira (2000), apresentam altas herdabilidades, variando de 74 a 86\%. Por outro lado, a correlação pode ser desfavorável. Isto significa que a seleção de um caráter poderá prejudicar outro, à medida que essa seleção estiver agindo no sentido contrário ao desejado. Em melancia, observa-se que frutos pequenos apresentam maior quantidade de sementes em determinada quantidade de polpa, o que é indesejável. Nestes casos, deve-se ter cuidado, pois às vezes é preciso o desenvolvimento de dois programas de melhoramento, cada um visando melhorar uma determinada característica.

Poucos trabalhos sobre correlações entre caracteres de melancia têm sido relatados. Sachan \& Tikka (1971) observaram que a produção de frutos apresentou correlação com o número de ramos primários, número de dias para o aparecimento da primeira flor feminina e peso de frutos. Já Sidhu \& Brar (1981), verificaram que a produção de frutos por planta correlacionou-se positivamente com peso de 100 sementes e peso de frutos, ao passo que sólidos solúveis totais e número de sementes por quilo de polpa apresentaram correlação negativa com a produção. Também foi constatada correlação positiva entre o número de frutos por planta e a produção de frutos e correlação negativa entre o número de frutos por planta e o peso de frutos (Partap et al., 1984), bem como associação entre a cor da polpa e o teor de sólidos solúveis (Abd El-Hafez et al., 1985). Foram detectadas, ainda, correlações entre a produção de frutos por planta com o comprimento do ramo, número de ramos por planta, peso e comprimento de frutos (Prasad et al., 1988).

Em decorrência do exposto, este trabalho foi executado com o objetivo de estimar as correlações genotípicas, fenotípicas e de ambiente entre dez caracteres de melancia, de modo que possa contribuir na orientação de programas de melhoramento genético.

\section{MATERIAL E MÉTODOS}

Na UNESP, campus de Jaboticabal, foram obtidas as sementes híbridas, em casa de vegetação. As cultivares de origem americana Charleston Gray, Crimson Sweet e New Hampshire Midget e os acessos B9, M7, P14 e B13, foram utilizados como genitores e cruzados em todas as combinações possíveis. Os acessos B9, B13, P14 e M7 são populações tradicionais coletadas, respectivamente, na Bahia, em Pernambuco e no Maranhão, sendo conservadas, $e x$ situ, no Banco Ativo de Germoplasma de Cucurbitáceas da Embrapa Semi-Árido (Queiróz, 1993, 1998). Estas populações divergem para uma série de caracteres, especialmente relacionados ao fruto, visto que os acessos de germoplasma apresentam cor da polpa variando de rósea a branca e baixo teor de sólidos solúveis, ao passo que as variedades americanas apresentam cor da polpa vermelha intensa e brix alto (Queiróz, 1993; Queiróz et al., 1996; Ferreira, 1996).

A avaliação em campo dos genitores, dos híbridos $\mathrm{F}_{1}$ e recíprocos, foi conduzida na estação experimental da Embrapa Semi-Árido, em Juazeiro (BA). Foi utilizado o delineamento em blocos ao acaso com quatro repetições e cada parcela foi composta por uma fileira com seis plantas, cujo espaçamento foi de 2,5 $\mathrm{m}$ entre fileiras e 1,0 m entre plantas.

Foram avaliados o número de dias para o aparecimento da primeira flor feminina (FF); número de frutos por planta $(\mathrm{NF})$; peso de frutos por planta $(\mathrm{PF}$, em $\mathrm{kg}$ ); cor (CP) e espessura (EP, em cm) da polpa; diâmetro longitudinal (DL, em $\mathrm{cm}$ ) e transversal (DT, em $\mathrm{cm}$ ) de frutos; teor de sólidos solúveis (TS, em $\left.{ }^{\circ} \mathrm{Brix}\right)$; número de sementes (NS) e peso de 100 sementes (PS, em g) por fruto. A cor dos 
Tabela 1. Coeficientes de correlação genotípica $(r G)$, fenotípica $(r F)$ e ambiental $(r E)$ entre dez caracteres avaliados em cruzamentos dialélicos, entre sete genitores de melancia. Petrolina, Embrapa Semi-Árido, 1996.

\begin{tabular}{|c|c|c|c|c|c|c|c|c|c|c|}
\hline Caracteres & $r$ & NF & PF & $\mathrm{CP}$ & EP & DL & DT & TS & NS & PS \\
\hline & $G$ & $0,48^{* *}$ & $-0,09 n s$ & $0,65^{* *}$ & $-0,08 n s$ & $-0,29^{*}$ & $0,02 \mathrm{~ns}$ & $-0,19 n s$ & $0,15 \mathrm{~ns}$ & $-0,19 n s$ \\
\hline \multirow[t]{3}{*}{ FF } & $\mathrm{F}$ & $0,41^{* *}$ & $-0,09 \mathrm{~ns}$ & $0,60^{* *}$ & $-0,08 n s$ & $-0,28 \mathrm{~ns}$ & $0,01 \mathrm{~ns}$ & $-0,17 \mathrm{~ns}$ & $0,12 \mathrm{~ns}$ & $-0,18 \mathrm{~ns}$ \\
\hline & E & $-0,19 \mathrm{~ns}$ & $-0,13 n s$ & $0,09 \mathrm{~ns}$ & $-0,10 \mathrm{~ns}$ & $-0,19 \mathrm{~ns}$ & $-0,09 \mathrm{~ns}$ & $0,01 \mathrm{~ns}$ & $-0,04 n s$ & $-0,08 \mathrm{~ns}$ \\
\hline & $G$ & & $-0,75^{* *}$ & $0,69^{* *}$ & $-0,57^{* *}$ & $-0,67^{* *}$ & $-0,54^{* *}$ & $-0,78^{* *}$ & $0,39^{* *}$ & $0,17 \mathrm{~ns}$ \\
\hline \multirow[t]{3}{*}{ NF } & $\mathrm{F}$ & & $-0,71^{* *}$ & $0,67^{* *}$ & $-0,54^{* *}$ & $-0,63^{* *}$ & $-0,49^{* *}$ & $-0,74^{* *}$ & $0,35^{\star}$ & $0,16 \mathrm{~ns}$ \\
\hline & $E$ & & $-0,06 \mathrm{~ns}$ & $0,17^{*}$ & $0,06 \mathrm{~ns}$ & $0,07 \mathrm{~ns}$ & $0,09 \mathrm{~ns}$ & $-0,12 \mathrm{~ns}$ & $0,10 \mathrm{~ns}$ & $0,01 \mathrm{~ns}$ \\
\hline & $G$ & & & $-0,47^{* *}$ & $0,74^{* *}$ & $0,76^{* *}$ & $0,79^{* *}$ & $0,87^{* *}$ & $-0,37^{* *}$ & $-0,27 n s$ \\
\hline \multirow[t]{3}{*}{ PF } & $\mathrm{F}$ & & & $-0,47^{* *}$ & $0,74^{* *}$ & $0,75^{* *}$ & $0,78^{* *}$ & $0,85^{* *}$ & $-0,30^{*}$ & $-0,25 \mathrm{~ns}$ \\
\hline & $E$ & & & $-0,28^{* *}$ & $0,60^{*}$ & $0,50^{\star *}$ & $0,57^{* *}$ & $0,37^{* *}$ & $0,31^{* *}$ & $0,09 \mathrm{~ns}$ \\
\hline & $G$ & & & & $-0,56^{* *}$ & $-0,32^{*}$ & $-0,44^{* *}$ & $-0,74^{* *}$ & $0,39^{* *}$ & $0,31^{* *}$ \\
\hline \multirow[t]{3}{*}{ CP } & $\mathrm{F}$ & & & & $-0,54^{* *}$ & $-0,31^{*}$ & $-0,43^{* *}$ & $-0,72^{* *}$ & $0,35^{*}$ & $0,30^{*}$ \\
\hline & $E$ & & & & $-0,23^{* *}$ & $-0,21^{*}$ & $-0,17^{*}$ & $-0,35^{* *}$ & $-0,05 n s$ & $0,10 \mathrm{~ns}$ \\
\hline & $G$ & & & & & $0,23 \mathrm{~ns}$ & $0,99^{* *}$ & $0,87^{* *}$ & $-0,24 n s$ & $-0,64^{* *}$ \\
\hline \multirow[t]{3}{*}{ EP } & $\mathrm{F}$ & & & & & $0,24 \mathrm{~ns}$ & $0,98^{* *}$ & $0,84^{* *}$ & $-0,19 n s$ & $-0,61^{* *}$ \\
\hline & $E$ & & & & & $0,51^{* *}$ & $0,81^{* *}$ & $0,26^{* *}$ & $0,36^{* *}$ & $0,11 \mathrm{~ns}$ \\
\hline & $\mathrm{G}$ & & & & & & $0,28^{*}$ & $0,51^{* *}$ & $-0,13 n s$ & $0,26 n s$ \\
\hline \multirow[t]{3}{*}{ DL } & $\mathrm{F}$ & & & & & & $0,29^{*}$ & $0,50^{* *}$ & $-0,11 \mathrm{~ns}$ & $0,26 \mathrm{~ns}$ \\
\hline & $E$ & & & & & & $0,48^{* *}$ & $0,32^{* *}$ & $0,18^{*}$ & $0,04 \mathrm{~ns}$ \\
\hline & $\mathrm{G}$ & & & & & & & $0,86^{* *}$ & $-0,19 \mathrm{~ns}$ & $-0,61^{* *}$ \\
\hline \multirow[t]{3}{*}{ DT } & $\mathrm{F}$ & & & & & & & $0,83^{* *}$ & $-0,14 n s$ & $-0,57^{* *}$ \\
\hline & $E$ & & & & & & & $0,26^{* *}$ & $0,33^{* *}$ & $0,26^{* *}$ \\
\hline & $G$ & & & & & & & & $-0,40^{* *}$ & $-0,54^{* *}$ \\
\hline \multirow[t]{3}{*}{ TS } & $\mathrm{F}$ & & & & & & & & $-0,36^{* *}$ & $-0,51^{* *}$ \\
\hline & $E$ & & & & & & & & $-0,09 \mathrm{~ns}$ & $-0,02 n s$ \\
\hline & $G$ & & & & & & & & & $0,17 \mathrm{~ns}$ \\
\hline \multirow[t]{2}{*}{ NS } & $F$ & & & & & & & & & $0,16 \mathrm{~ns}$ \\
\hline & $\mathrm{E}$ & & & & & & & & & $0,08 \mathrm{~ns}$ \\
\hline
\end{tabular}

Significativo ao nível de $1 \%$ de probabilidade $\left({ }^{* *}\right), 5 \%$ de probabilidade $\left({ }^{*}\right)$ e não significativo ao nível de $5 \%$ de probabilidade (ns), pelo teste F.

$\mathrm{FF}=$ número de dias para o aparecimento da primeira flor feminina; $\mathrm{NF}=$ número de frutos por planta; $\mathrm{PF}=$ peso de frutos por planta; $\mathrm{CP}$ = cor da polpa; $\mathrm{EP}=$ espessura da polpa; $\mathrm{DL}=$ diâmetro longitudinal de frutos; $\mathrm{DT}=$ diâmetro transversal de frutos; $\mathrm{TS}=$ teor de sólidos solúveis; $\mathrm{NS}$ = número de sementes por fruto; $\mathrm{PS}=$ peso de cem sementes por fruto.

frutos foi avaliada de acordo com a escala de notas proposta neste estudo: $1=$ vermelha intensa; $2=$ vermelha; $3=$ vermelha clara; 4 = rósea e $5=$ branca.

As estimativas dos coeficientes de correlação genotípica $(r G)$, fenotípica $(r F)$ e de ambiente $(r E)$ foram obtidas mediante análises de covariâncias, combinando os dados dos dez caracteres em todas as formas possíveis (Cruz \& Regazzi, 1994). Foi empregado o teste $t$ para examinar a significância estatística das estimativas ao nível de $1 \%$ e $5 \%$ de probabilidade. As análises estatísticas foram realizadas no programa GENES.

\section{RESULTADOS E DISCUSSÃO}

Em relação aos coeficientes $(r G)$ e $(r F)$, foi verificada uma grande similaridade entre os pares de caracteres, em relação aos sinais, a magnitude e o nível de significância, com exceção apenas da correlação entre FF e DL, com $r G=-0,29 *$ e $r F=-0,28 n s$ (Tabela 1). Em decorrência dessa similaridade, bem como pelo maior valor prático nos trabalhos de melhoramento, as correlações genotípicas serão analisadas com maior detalhe.

Em $95,5 \%$ dos pares de caracteres, as correlações genotípicas foram iguais ou superiores às correlações fenotípicas, assim como estas duas, em $82,2 \%$ dos casos foram superiores às correlações de ambiente. Verificou-se também que nas 45 combinações possíveis entre os dez caracteres, em apenas oito a correlação ambiental foi superior à genotípica. A correlação de ambiente, para a maioria dos pares de caracteres, foi reduzida, ou seja, menor que 0,5 , constatando-se que houve maior contribuição dos fatores genéticos em relação aos fatores ambientais nas correlações entre os caracteres. No entanto, o peso de fruto apresentou correlação ambiental ao re- 
Correlações genotípicas, fenotípicas e de ambiente entre dez caracteres de melancia e suas implicações para o melhoramento genético

Tabela 2. Médias de dez caracteres avaliados em sete populações de melancia. Petrolina, Embrapa Semi-Árido, 1996.

\begin{tabular}{crrrcrrr}
\hline \multirow{2}{*}{ Caracteres } & \multicolumn{7}{c}{ Populações } \\
\cline { 2 - 8 } & $\mathbf{1}$ & $\mathbf{2}$ & $\mathbf{3}$ & $\mathbf{4}$ & $\mathbf{5}$ & $\mathbf{6}$ & $\mathbf{7}$ \\
\hline FF & $37,25 \mathrm{a}$ & $29,00 \mathrm{~b}$ & $32,50 \mathrm{~b}$ & $28,58 \mathrm{~b}$ & $29,75 \mathrm{~b}$ & $32,25 \mathrm{~b}$ & $28,75 \mathrm{~b}$ \\
NF & $8,27 \mathrm{a}$ & $1,17 \mathrm{~d}$ & $1,27 \mathrm{~d}$ & $2,70 \mathrm{~cd}$ & $2,85 \mathrm{~cd}$ & $10,07 \mathrm{a}$ & $5,05 \mathrm{bc}$ \\
PF & $1,45 \mathrm{~b}$ & $6,60 \mathrm{a}$ & $6,10 \mathrm{a}$ & $1,90 \mathrm{~b}$ & $3,27 \mathrm{~b}$ & $1,45 \mathrm{~b}$ & $3,02 \mathrm{~b}$ \\
$\mathrm{CP}$ & $4,32 \mathrm{a}$ & $1,15 \mathrm{~d}$ & $1,32 \mathrm{~d}$ & $2,07 \mathrm{c}$ & $3,15 \mathrm{~b}$ & $3,97 \mathrm{a}$ & $3,30 \mathrm{~b}$ \\
EP & $11,15 \mathrm{c}$ & $15,22 \mathrm{~b}$ & $19,30 \mathrm{a}$ & $11,82 \mathrm{c}$ & $11,47 \mathrm{c}$ & $11,15 \mathrm{c}$ & $12,32 \mathrm{c}$ \\
DL & $14,00 \mathrm{~d}$ & $37,30 \mathrm{a}$ & $24,00 \mathrm{bc}$ & $17,15 \mathrm{~cd}$ & $31,30 \mathrm{ab}$ & $15,90 \mathrm{~d}$ & $27,97 \mathrm{~b}$ \\
DT & $13,52 \mathrm{c}$ & $17,27 \mathrm{~b}$ & $21,30 \mathrm{a}$ & $13,27 \mathrm{c}$ & $13,85 \mathrm{c}$ & $13,22 \mathrm{c}$ & $14,65 \mathrm{c}$ \\
TS & $5,72 \mathrm{~b}$ & $9,47 \mathrm{a}$ & $10,82 \mathrm{a}$ & $6,15 \mathrm{bc}$ & $7,42 \mathrm{~b}$ & $5,42 \mathrm{c}$ & $6,62 \mathrm{bc}$ \\
NS & $511,25 \mathrm{a}$ & $355,50 \mathrm{c}$ & $352,75 \mathrm{c}$ & $472,00 \mathrm{bc}$ & $576,5 \mathrm{~b} 0$ & $546,25 \mathrm{~b}$ & $643,75 \mathrm{a}$ \\
PS & $9,14 \mathrm{a}$ & $8,61 \mathrm{a}$ & $4,11 \mathrm{a}$ & $8,77 \mathrm{a}$ & $9,51 \mathrm{a}$ & $8,02 \mathrm{a}$ & $9,87 \mathrm{a}$ \\
\hline
\end{tabular}

Médias seguidas da mesma letra, nas linhas, não diferem significativamente ao nível de $5 \%$ de probabilidade pelo Teste de Tukey. 1 = B9; 2 = Charleston Gray; 3 = Crimson Sweet; $4=$ New Hampshire Midget; $5=\mathrm{M} 7 ; 6=\mathrm{P} 14 ; 7=\mathrm{B} 13$. FF = número de dias para o aparecimento da primeira flor feminina; $\mathrm{NF}=$ número de frutos por planta; $\mathrm{PF}=$ peso de frutos por planta; $\mathrm{CP}=$ cor da polpa; $\mathrm{EP}=\mathrm{espessura}$ da polpa; DL = diâmetro longitudinal de frutos; DT = diâmetro transversal de frutos; TS = teor de sólidos solúveis; $\mathrm{NS}=$ número de sementes por fruto; PS = peso de cem sementes por fruto.

dor de 0,5 com espessura da polpa e tamanho do fruto, assim como a correlação entre espessura da polpa e diâmetro longitudinal, indicando que estas correlações foram mais influenciadas pelo ambiente do que as demais. A maioria dos coeficientes de correlação genotípica foi estatisticamente significativa a $1 \%$ e $5 \%$ de probabilidade, sendo que em $44,4 \%$ dos casos as correlações foram superiores a 0,5 (Tabela 1 ).

A correlação entre o número de frutos por planta e o peso de frutos foi negativa e de valor 0,75 , significando que com o aumento do número de frutos por planta os mesmos apresentaram menor peso, fato encontrado também por Partap et al. (1984). Analisando-se as demais correlações envolvendo o número de frutos por planta, observa-se que este caráter correlacionou-se também com a cor, a espessura e o teor de sólidos solúveis da polpa e com o tamanho de frutos (em função de DL e DT) (Tabela 1). Assim, nas populações estudadas, quanto maior o número de frutos por planta, menor será o peso, o tamanho, a espessura e o teor de sólidos solúveis da polpa, desses frutos, bem como maior será a tendência para cor branca da polpa. Portanto, o melhorista não deve selecionar para características da polpa como espessura, teor de sólidos solúveis e cor com base no número de frutos por planta.

As populações tradicionais do Nordeste, $\mathrm{B} 9$ e P14, apresentaram maior número de frutos por planta e frutos com menor peso e tamanho. As populações B9, P14 e B13 também foram mais produtivas (NF $\mathrm{x} P F)$, pois produziram respectivamente 15,$2 ; 14,6$ e 11,9 kg por planta, em comparação com as cultivares New H. Midget (5,1 kg/planta), Charleston Gray (7,7 kg/ planta) e Crimson Sweet (5,1 kg/planta). Contudo, elas apresentaram cor da polpa rósea e baixo teor de sólidos solúveis (Tabela 2). Apesar das correlações entre o número de frutos por planta e a cor e o teor de sólidos solúveis da polpa terem sido elevadas, existe a possibilidade de obter plantas recombinantes que sejam prolíficas (alta produção de frutos por planta) e apresentem frutos pequenos, vermelhos $\mathrm{e}$ doces. Esta afirmativa é reforçada pelo fato de Ferreira (1996) constatar que nestas populações há uma alta frequiência de alelos favoráveis para estes caracteres, uma vez que houve predomínio de efeitos gênicos aditivos.

Além disso, podem ser obtidas populações segregantes a partir de cruzamentos envolvendo as populações B9 e P14 e as cultivares Charleston Gray e Crimson Sweet, que apresentaram frutos com polpa vermelha e alto teor de sólidos solúveis. Ferreira (2000), por exemplo, a partir de uma população base obtida pelo intercruzamento de 'Crimson Sweet' e P14, selecionou progênies maternas e autofecundadas prolíficas e que apresentavam frutos pequenos, vermelhos e doces. Tais resultados reforçam a ampla variabilidade genética apresentada pelas populações tradicionais do Nordeste, assim como a eficiência em se efetuar um pré-melhoramento dessas variedades através de intercruzamentos com outras populações.

Em relação às correlações envolvendo o peso de frutos e outras características relevantes para o melhoramento de melancia e considerando as populações estudadas, foi verificado que esse caráter está correlacionado também com o tamanho do fruto e com a espessura e o teor de sólidos solúveis da polpa, pois frutos maiores e consequentemente mais pesados apresentaram maior espessura e teor de sólidos solúveis da polpa e vice-versa (Tabela 1). Estes resultados estão em conformidade com as médias fenotípicas dos genitores, uma vez que 'Charleston Gray' e 'Crimson Sweet' apresentaram maior PF, EP, DL, DT e TS quando comparadas com as demais populações (Tabela 2).

Por outro lado, precocidade, teor de sólidos solúveis e espessura da polpa podem ser selecionadas com base na cor da polpa, uma vez que esta característica, segundo Ferreira (2000), apresenta uma alta herdabilidade $(0,86)$ e as correlações $\mathrm{FF}$ e $\mathrm{CP}, \mathrm{CP}$ e EP e CP e TS, dão indícios de que quanto mais vermelha a polpa do fruto, maior será o teor de sólidos solúveis e a espessura da polpa desse fruto, assim como mais precoce será a planta. 
O número de sementes por fruto apresentou correlações significativas, principalmente com o peso de fruto e número de frutos por planta, entretanto as correlações foram abaixo de 0,4 (Tabela 1), indicando que será possível a seleção de plantas que tenham frutos pequenos com uma quantidade menor de sementes. Outra alternativa para reduzir a quantidade de sementes nos frutos é a produção de híbridos triplóides a partir do cruzamento de linhas tetraplóides com linhas diplóides (Souza et al., 1999).

Embora algumas correlações indesejáveis entre os caracteres tenham sido altas, não se configuraram em associação completa, sendo possível obter recombinantes que sejam promissores para os caracteres mais importantes economicamente, como por exemplo, para o tamanho, o peso e o número de frutos por planta e para a espessura, o teor de sólidos solúveis e a cor da polpa. Um modo indicado para atingir essa meta seria a realização de cruzamentos entre populações contrastantes a exemplo do realizado por Ferreira (2000). Assim, intercruzamentos envolvendo as populações de melancia $\mathrm{B} 9, \mathrm{~B} 13$ e P14 e as variedades comerciais Charleston Gray e Crimson Sweet, como já comentado, podem originar progênies precoces, prolíficas, com frutos pequenos, vermelhos e doces.

Uma vez obtidas as populações base entre tipos contrastantes, principalmente quanto à prolificidade, poderão ser usados métodos de melhoramento de populações como seleção recorrente recíproca utilizando o método do híbrido críptico (Paterniani \& Miranda Filho, 1978), a fim de se obter linhagens superiores para a síntese de híbridos ou para a síntese de populações melhoradas que atendam às exigências dos produtores e consumidores.

Acredita-se também que o emprego de marcadores moleculares seja uma ferramenta de interesse, uma vez que possibilita mapear e, conseqüentemente, localizar os genes que controlam os caracteres mais importantes para o melhoramento da melancia. Dependendo da distância cromossômica entre eles haverá ou não a possibilidade de desfazer as associações indesejáveis. Mapeamentos genéticos estão sendo realizados em algumas cucurbitáceas (Navot et al., 1990; Kennard et al., 1994; Baudracco-Arnas \& Pitrat, 1996; Lee et al., 1996), porém todos fora do Brasil. Assim, esta área deve ser iniciada em nosso país, a fim de que genes de melancia, nas populações disponíveis, sejam mapeados e estudados, contribuindo com os trabalhos já existentes.

\section{AGRADECIMENTOS}

Os autores agradecem aos funcionários da UNESP e da Embrapa Semi-Árido que contribuíram para a concretização deste trabalho, assim como pelo apoio financeiro dessas instituições e do CNPq, pela concessão da bolsa de estudos a primeira autora.

\section{LITERATURA CITADA}

ABD EL-HAFEZ, A.A.; GAAFER, A.K.; ALLAM, A.M.M. Inheritance of flesh colour, seed coat cracks and total soluble solids in vatermelon and their genetic relations II. Quantitative characters and the association between various characters. Acta Agronomica Scientiarum Hungaricae, v. 34, n. 112, p. 84-89, 1985.

ASSIS, J.G.A. Caracterização isoenzimática e variabilidade genética de populações de melancia (Citrullus lanatus) do nordeste brasileiro. Piracicaba: ESALQ, 1999. 76 p. (Tese doutorado). ASSIS, J.G.A. Estudos genéticos no gênero Citrullus. Jaboticabal: FCAV, 1994. 99 p. (Tese mestrado).

BAUDRACCO-ARNAS, S.; PITRAT, M. A genetic map of melon (Cucumis melo L.) with RFLP, RAPD, isozyme, disease resistance and morphological markers. Theoretical and Applied Genetics, v. 93, p. 57-64, 1996.

CRUZ, C.D.; MIRANDA, J.E.C.; COSTA, C.P. Correlações, efeitos diretos e indiretos de caracteres agronômicos sobre a produção de pimentão (Capsicum annuum L.). Revista Brasileira de Genética, Ribeirão Preto, v. 11, n. 4, p. 921-928, 1988. CRUZ, C.D., REGAZZI, A.J. Modelos Biométricos Aplicados ao Melhoramento Genético. Viçosa: UFV, Imprensa Universitária, 1994. 390 p.

DIAS, R.C.S.; QUEIRÓZ, M.A.; MENEZES, M. Fontes de resistência em melancia a Didymella bryoniae. Horticultura Brasileira, Brasília, v. 14, n. 1, p. $15-18,1996$.

FERREIRA, M.A.J.F. Sistema reprodutivo e potencial para o melhoramento genético de uma população de melancia Citrullus lanatus (Thunb.) Matsum. \& Nakai. Piracicaba: ESALQ, 2000. 148 p. (Tese doutorado).

FERREIRA, M.A.J.F.; VENCOVSKY, R.; VIEIRA, M.L.C.;QUEIROZ, M.A. Outcrossing rate and implications for the improvement of a segragating population of watermelon. Acta Horticulturae, n. 510, p. 47-54, 2000.

FERREIRA, M.A.J.F. Análise dialélica em melancia Citrullus lanatus (Thunb.) Mansf. Jaboticabal: FCAV, 1996. 83 p. (Tese mestrado). IBGE. Rio de Janeiro, v. 51, 1991. 1024 p.

IBGE. http://www.ibge.gov.br/informacoes/ estat1.htm. 23 de nov de 1998.

KENNARD, W.C.; POETTER, K.; DIJKHUIZEN, A.; MEGLIC, V.; STAUB, J.E.; HAVEY, M.J. Linkages among RFLP, RAPD, isozyme, disease resistance and morphological markers in narrow and wide crosses of cucumber. Theoretical and Applied Genetics, v. 89, p. 42-48, 1994.
LEE, S.J.; SHIN, J.S.; PARK, K.W.; HONG, Y.P. Detection of genetics diversity using RAPD-PCR and sugar analysis in watermelon [Citrullus lanatus (Thunb.) Mansf.] germplasm. Theoretical and Applied Genetics, v. 92, p. 719-725, 1996.

NAVOT, N.; SARFATTI, M.; ZAMIR, D. Linkage relationships of genes affecting bitterness and flesh color in watermelon. The Journal of Heredity, $\mathrm{v}$. 81 , n. 2, p. 162-165, 1990.

PATERNIANI, E.; MIRANDA FILHO, J.B. Melhoramento de populações. In: PATERNIANI, E. (coord.). Melhoramento e produção do milho no Brasil. Piracicaba: ESALQ, p. 202-256, 1978.

PARTAP, P.S. Biparental crossing in watermelon (Citrullus lanatus (Thunb.) Schard.). Genetica Agraria, v. 38, n. 4, p. 379-385, 1984.

PRASAD, L.; GAUTAM, N.C.; SINGH, S.P. Studies on genetic variability and character association in watermelon (Citrullus lanatus (Thunb.) Mansf.). Vegetable Science, v. 15, n. 1, p. 86-94, 1988.

QUEIRÓZ, M.A. Cucurbitáceas no semi-árido do Nordeste brasileiro: resgate, conservação e uso. In: ENCONTRO SOBRE TEMAS DE GENÉTICAE MELHORAMENTO, 15., 1998, Piracicaba. Anais... Piracicaba: ESALQ, 1998. p. 1-12.

QUEIRÓZ, M.A. Potencial de germoplasma de cucurbitáceas no nordeste brasileiro. Horticultura Brasileira, Brasília, v. 11, n. 1, p. 7-9, 1993.

QUEIRÓZ, M.A.; DIAS, R.C.S.; SOUZA, F.F; FERREIRA, M.A.J.F.; ASSIS, J.G.A.; BORGES, R.M.E.; ROMÃO, R.L.; RAMOS, S.R.R.; COSTA, M.S.V.; MOURA, M.C.C.L. Recursos genéticos e melhoramento de melancia no nordeste brasileiro. In: QUEIRÓZ, M.A.; GOEDERT, C.O.; RAMOS, S.R.R. Recursos genéticos e melhoramento de plantas para o nordeste brasileiro (on line). Versão 1.0. Petrolina: Embrapa Semi-Árido/Brasília: Embrapa Recursos Genéticos e Biotecnologia, 1999. Home page: http: \www.cpatsa.embrapa.br QUEIROZ, M.A.; DIAS, R.C.S.; SOUZA, F.F.; FERREIRA, M.A.J.F.; BORGES, R.M.E. Watermelon breeding in Brazil. Acta Horticulturae, n. 510, p. 105-112, 2000.

QUEIRÓZ, M.A.; ROMÃO, R.L.; DIAS, R.C.S.; ASSIS, J.G.A.; BORGES, R.M.E.; FERREIRA, M.A.J.F.; RAMOS, S.R.R.; COSTA, M.S.V.; MOURA, M.C.C.L. Watermelon germplasm bank for the Northeast of Brazil. An integrated approach In: EUCARPIA MEETING ON CUCURBITS GENETICS AND BREEDIND, 6., 1996, Malaga. Proceedings... Malaga: European Association for Research on Plant Breeding, 1996. p. 97-103.

ROMÃO, R.L. Dinâmica evolutiva e variabilidade de populações de melancia Citrullus lanatus (Thunb.) Matsum. \& Nakai. em três regiões do nordeste brasileiro. Piracicaba: ESALQ, 1995. 75 p. (Tese mestrado).

SACHAN, C.P.; TIKKA, S.B.B. Genetic variability and correlation studies in watermelon (Citrullus lanatus Thunb. Mansf.). Rajasthan Journal Agricultural Science, v. 2, n. 2, p. 91-96, 1971.

SIDHU, A.S.; BRAR, J.S. Correlation and path coefficient analysis for yield, quality and earliness in watermelon (Citrullus lanatus Thunb. Mansf.). Indian Journal of Agricultural Research, v. 15, n. 1, p. 33-37, 1981. In: Plant Breeding Abstracts, v. 52, n. 9, p. 730, 1983 (Abstract 7982).

SOUZA, F.F.; QUEIRÓZ, M.A.; DIAS, R.C.S. Melancia sem sementes: desenvolvimento e avaliação de híbridos triplóides experimentais de melancia. Biotecnologia Ciência \& Desenvolvimento, v. 3, n. 9, p. 90-95, 1999.

VENCOVSKY, R.; BARRIGA, P. Genética Biométrica no Melhoramento. Ribeirão Preto: SBG, 1992. 496 p. 